\section{Hemophagocytic Lymphohistiocytosis (HLH) Triggered by Wasp Venom Immunotherapy Is Rare but Noteworthy}

Nittner-Marszalska $\mathrm{M}^{1}$, Kosińska M ${ }^{1}$, Suchnicki K ${ }^{2}$, Rzeszutko $\mathrm{M}^{3}$, Pomorska $\mathrm{M}^{4}$, Durek $\mathrm{G}^{5}$, Panaszek B ${ }^{1}$

${ }^{1}$ Department of Internal Medicine and Allergology, Wroclaw Medical University, Wroclaw, Poland

${ }^{2}$ Lower Silesian Center for Cellular Transplantation with National Bone Marrow Donor Registry, Wroclaw, Poland

${ }^{3}$ Department of Pathomorphology, Wroclaw Medical University, Wroclaw, Poland

${ }^{4}$ Department of Pathological Anatomy, Wroclaw Medical University, Wroclaw, Poland

${ }^{5}$ Department of Anesthesiology and Intensive Therapy, Wroclaw Medical University, Wroclaw, Poland

J Investig Allergol Clin Immunol 2019; Vol. 29(1): 49-51 doi: $10.18176 /$ jiaci.0322

Key words: HLH; wasp venom immunotherapy; hemophagocytic lymphohistiocytosis; VIT.

Palabras clave: LHH. Inmunoterapia con veneno de himenópteros. Linfohistiocitosis hemofagocítica. IVH.

Insect venom immunotherapy (VIT) can trigger hemophagocytic lymphohistiocytosis (HLH) and reactivate inflammation. The management of adverse reactions caused by VIT is a common problem in daily clinical practice [1].

We report a case of HLH that occurred during the course of immunotherapy with wasp venom. A 49-year-old woman was prescribed VIT after experiencing an IgE-dependent anaphylactic reaction to a wasp sting (Mueller scale, grade 3 ). The reaction took the form of weakness, urticaria, and dyspnea. Intradermal testing (IDT) with Vespula species venom $(0.1 \mu \mathrm{g} / \mathrm{mL}=5-6 \mathrm{~mm})$, serum-specific $\operatorname{IgE}(\mathrm{sIgE})$ with wasp venom (4.22 IU/L), and IDT and sIgE with bee venom were negative (tryptase, $4.2 \mathrm{ng} / \mathrm{mL}$ ). The medical history was remarkable only for mild hypertension and osteoporosis. There were no complications during ultrarush VIT (Pharmalgen wasp venom, Vespula species, AlkAbello; cumulative dose, $111.1 \mu \mathrm{g}$ ) and after 2 maintenance doses (Alutard). The third maintenance dose was followed (after 24 hours) by bilateral impaired vision and temporary blindness. Ophthalmoscopy revealed multiple bilateral serous pigment epithelial detachments in the posterior poles involving the macular area. This observation was confirmed by optical coherence tomography (OCT). Local and systemic corticosteroid therapy was started and led to gradual improvement of anatomic features (partial resorption of subretinal fluid, as evidenced by OCT), followed by limited functional improvement. Serological tests did not show anticytomegalovirus IgM (anti-CMV $\operatorname{IgM})$.
VIT was discontinued. After a month, the patient visited our clinic to make arrangements for further treatment of hymenoptera venom allergy. She reported headaches and a feeling of weakness. Physical examination revealed the following results: body temperature, $38^{\circ} \mathrm{C}$ (fever had persisted for a few weeks); heart rate, $120 \mathrm{bpm}$; blood pressure, 100/80 mmHg; bilateral hydrothorax; hepatosplenomegaly; ascites; and peripheral edema. The neurological examination revealed no abnormalities. The patient was admitted to hospital immediately. Test results obtained during hospitalization revealed the following: anemia (hemoglobin, 7.2-9.6 g/dL; erythrocytes, 2.6-3.59 $\left.10^{6} / \mu \mathrm{L}\right)$, trilineage cytopenia (thrombocytes, $40 \times 10^{3} / \mu \mathrm{L}$; leukocytes, $2 \times 10^{3} / \mu \mathrm{L}$ ), higher levels of inflammation markers (erythrocyte sedimentation rate, 130/h; C-reactive protein, 137.1-208.5 mg/L; D-dimers, $5.15 \mu \mathrm{g} / \mathrm{mL}$; procalcitonin, 4.33-5.89 ng/mL; ferritin, 1610 $\mathrm{ng} / \mathrm{mL}$ ), and liver cell injury (total protein, $4.9 \mathrm{~g} / \mathrm{L}$; albumin, $2.6 \mathrm{~g} / \mathrm{L}$; alanine transaminase, $120 \mathrm{U} / \mathrm{L} ; \gamma$-glutamyltransferase, $100 \mathrm{U} / \mathrm{L}$; cholesterol, $119 \mathrm{mg} / \mathrm{dL}$; prothrombin ratio, 56\%); hypertriglyceridemia, $450 \mathrm{mg} / \mathrm{dL}$ ). The patient's symptoms were not related to bacterial or fungal infections; blood, urine, sputum, stool, and throat cultures tested for bacterial and fungal infections (Aspergillus, Candida, Cryptococcus), tuberculosis, and borreliosis were negative. Serological tests ruled out infection by human immunodeficiency virus, viral hepatitis $\mathrm{B}$ and $\mathrm{C}$, and Epstein-Barr virus but evidenced $\mathrm{CMV}$ infection (CMV-DNA-positive; anti-CMV IgG, 91.1 AU/mL; antiCMV IgM-negative). Immunodeficiency was not detected. Imaging procedures (chest x-ray, computed tomography [head, abdomen, and pelvis], transvaginal sonography) revealed no neoplasms. Screening for autoimmune diseases (connective tissue disease) was negative. We were not able to establish the etiology of the symptoms despite intensive investigation and diagnostic testing. Treatment included empiric antibiotic therapy (ceftriaxone, imipenem/cilastatin), blood transfusion,

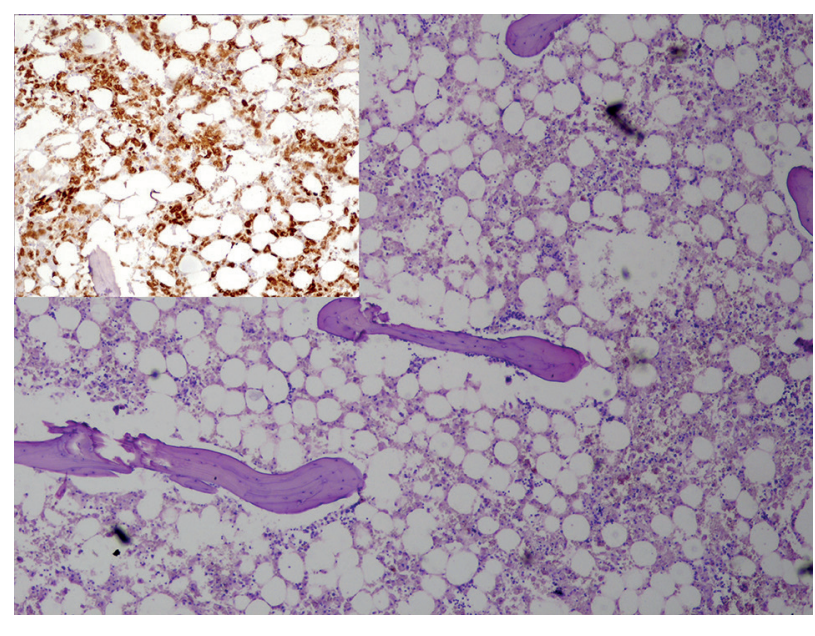

Figure. Histology and immunohistology of a postmortem bone marrow specimen. Numerous activated macrophages phagocytosing hematopoietic elements. Dispersed macrophages among bone marrow cells on the right (HE stain, magnification $\times 100$ ) and confirmation of a $\mathrm{CD} 68^{+}$reaction by immunohistochemistry. Insert, upper left corner; immunohistochemical stain, magnification $\times 100$. 
albumin infusion, and electrolyte supplementation. Since the patient met the criteria for a diagnosis of HLH [2], high doses of corticosteroids were administered, and treatment with etoposide was scheduled. Despite these efforts, the patient died of multiple organ dysfunction syndrome. Autopsy showed macrophage activation in bone marrow with hemophagocytosis (Figure). Morphological, histological, and immunostaining profiles were confirmed, revealing the characteristic hemophagocytosis typical of HLH.

HLH is a rare, potentially fatal disease that manifests with symptoms of infection caused by hyperactivation of the immune system and involves secondary hypercytokinemia, as well as proliferation of well-differentiated macrophages/ histiocytes and their greater phagocytic activity [2]. The mechanisms for deactivation of the process are impaired. Detection of hemophagocytosis in the bone marrow, liver, and spleen is pathognomonic for HLH.

We can distinguish 2 forms of HLH: primary and secondary. The former may have genetic origins; it manifests during the first 2 years of life in $70 \%-80 \%$ of cases. The latter occurs in adults and is typically induced by infection, as well as by autoimmune or neoplastic processes $[3,4]$. To date, allergen immunotherapy has not been thought to trigger HLH.

Diagnosis of HLH is difficult, especially in adults, for several reasons. First, the disease is mostly observed in children. Second, the clinical picture and diagnostic criteria of HLH are nonspecific. Third, many other diseases have to be ruled out. And fourth, there is no gold standard confirmatory test (the recently available tests for soluble CD25 and the 51-Cr release assay are not available in many medical centers). As a result, the mean time from clinical suspicion to definitive diagnosis in adults, even in highly specialized centers, ranges from 1 to 27 days (mean, 5 days [21 in the present case]). This period may be longer in children (10-60 days [mean, 50 days]) [5].

The patient we report was diagnosed with HLH during the course of wasp venom immunotherapy. The initial symptoms were visual disturbances and fever. Few reports have been published on ophthalmic abnormalities associated with HLH $[6,7]$. The ocular features are nonspecific and may resemble those of leukemic or Purtscher retinopathy, acute posterior multifocal placoid pigment epitheliopathy, and Vogt-Koyanagi-Harada (VKH) disease. In the present case, HLH syndrome was preceded by multiple serous pigment epithelial detachments in the posterior poles of both eyes consistent with a VKH-like presentation. Since the retinal changes were bilateral and we did not identify any other causes for the ophthalmic findings, we are convinced they were uveal inflammatory reactions prodromal to development of HLH. The CMV infection detected during hospitalization does not seem to be a primary infection. Viewed in light of the patient's progress, it appears to be secondary in nature, that is, a reactivation of a latent infection in a critically ill patient. The coexisting viral infection seems to have affected prognosis [8].

Finally, while HLH is associated with macrophage activation in bone marrow affected by hemophagocytosis and with morphological, histological, and immunostaining profiles revealing characteristic hemophagocytosis indicate $\mathrm{HLH}$, the question in the present case is whether HLH is primary or secondary. The point is that many allegedly secondary HLH patients may actually have a latent genetic defect (eg, heterozygous defect, mutation resulting in partial protein expression) that can be triggered by factors disturbing immune homeostasis. There is a possibility that application of high doses of venom allergens in the course of VIT caused HLH in a predisposed individual. Ours is the first report on HLH occurring during allergen immunotherapy. The factors in favor of an association between the two in this particular case are potential triggering of HLH in a genetically predisposed adult after exposure to toxins or antigens, lack of other identifiable etiologic factors (another likely explanation of the occurrence of HLH), and a reasonable time relationship between the HLH event and its possible trigger. Still, despite the arguments presented, based on the WHO classification of drug-induced adverse events [9], we decided to classify the link between VIT and the ensuing HLH as possible, instead of probable, as we are not in a position to confirm the effect of stopping and then resuming VIT on the occurrence and course of HLH.

Although primary HLH is rare in adults, recent reports suggest that late onset familial HLH occurs more frequently than previously believed.

\section{Funding}

The authors declare that no funding was received for the present study.

\section{Conflicts of Interest}

The authors declare that they have no conflicts of interest.

\section{References}

1. Alfaya Arias $T$, Soriano Gomis V, Soto Mera T, Vega Castro A, Vega Gutierrez JM, Alonso Llamazares A, et al. Key Issues in Hymenoptera Venom Allergy: An Update. J Investig Allergol Clin Immunol. 2017;27:19-31.

2. Henter J-I, Horne A, Aricó M, Egeler RM, Filipovich $A H$, Imashuku S, et al. HLH-2004: diagnostic and therapeutic guidelines for hemophagocytic lymphohistiocytosis. Pediatr Blood Cancer. 2007;48:124-31.

3. Otrock ZK, Eby CS. Clinical characteristics, prognostic factors and outcomes of adult patients with hemophagocytic lymphohistiocytosis. Am J Hematol. 2015;90:220-4.

4. Machaczka M.M, Vaktnas J, Klimkowska M, Nahi H, Hagglund $\mathrm{H}$. Acquired haemophagocytotic lymphohistiocytosis associated with multiple myeloma. Medical Oncology. 2011;28:539-43.

5. Ferreira DG, do Val Rezende P, Murao M, Viana MB, de Oliveira BM. Hemophagocytic lymphohistiocytosis: a case of serie of a Brazilian institution. Rev Brasil Hemoter. 2014;36:437-41.

6. Gianella S, Schaer DJ, Schwarz U, Kurrer M, Heppner FL, Fehr $J$, et al. Retinal microangiopathy and rapidly fatal cerebral edema in a patient with adult onset Still's disease and concurrent macrophage activation syndrome. Am J Hematol. 2008;83:424-7.

7. Suhr KS, Chiang MF, Flynn JT, Engelbert M. Ocular involvement in hemophagocytic syndrome: a novel funduscopic 
manifestation and review of the literature. Retin Cases Brief Rep. 2016;10:345-8.

8. Cattaneo C, Oberti M, Skert C, Passi A, Farina M, Tozzi P, et al. Adult onset hemophagocytic lymphohistiocytosis prognosis is affected by underlying disease and coexisting viral infection: analysis of a single institution series of 35 patients. Hematol Oncol. 2016;06: doi:10.1002/hon2314

9. The use of the WHO-UMC system for standardised case causality assessment. Accessed from http://www.who. int/medicines/areas/quality_safety/safety_efficiacy/ WHOcausality_assesment.pdf

Manuscript received May 20, 2018; accepted for publication September 13, 2018.

Magdalena Kosińska

Department of Internal Medicine and Allergology

ul. Curie-Skłodowskiej 66

Wrocław 50-369, Poland

E-mail:wroblaha@yahoo.com 